\title{
Case Report of Diabetes Mellitus - II in Pindi Bhattian
}

\author{
Asif Bilal ${ }^{1}$ and Iqra Akbar ${ }^{2 *}$ \\ ${ }^{1}$ Faculty of Biological Sciences, Skies Up College of Science and Technology, Pakistan \\ ${ }^{2}$ Faculty of Biological Sciences, Dar-e-Arqam School and College, Pakistan
}

Submission: July 05, 2021; Published: July 13, 2021

*Corresponding author: Iqra Akbar, Faculty of Biological Sciences, Dar-e-Arqam School and College, Pakistan

Abstract

Diabetes is well known for causing acute and chronic problems, which might jeopardize one's health and quality of life. The various consequences of diabetes are caused by metabolic imbalances. To treat diabetes diseases without disrupting everyday activities, a wise lifestyle change is essential. It's a case report of XYZ is a 50-year-old housewife who has had type 2 diabetes for two years. The Patient has also been suffering from hypertension for last three years. It was before three years of diagnosis of diabetes. She has also has a family history. She is now treating with Tab. Doanil, Tab. Biforge, Tab. Diajard, and Insulin at daily basis. She is now maintaining her diet and does exercises to set her routine life well.

Keywords: Doanil; Biforge; Insulin; Hypertension; Diet; Exercise; Diabetes

\section{Background}

Diabetes is well known for causing acute and chronic problems, which might jeopardize one's health and quality of life. Several studies [1] have found that better blood glucose control in people with type 2 diabetes reduces the risk of complications. Type 2 diabetes is the result of a metabolic disorder caused by tissue resistance to insulin action and the pancreas' failure to regulate the amount of insulin released for glucose metabolism. The various consequences of diabetes are caused by metabolic imbalances. Adults aged 40 and up have a higher risk of developing type 2 diabetes. However, a recent trend suggests that minority ethnic children and adolescents, particularly African Americans and American Indians, are becoming more prone to type 2 diabetes [2]. With the rising prevalence of type 2 diabetes and the associated risk of significant consequences, aggressive self-management has become a top priority. Dietary control is sometimes referred to as the cornerstone, or first step, in the treatment of type 2 diabetes. Carbohydrate-rich foods serve a significant function in the diet. The glycemic index (GI) ranks foods based on their glycemic responses after eating.

The GI has been widely used in diabetes care in Australia, New Zealand, Canada, the United Kingdoms, and France for more over two decades [3]. According to the World Health Organization, including the GI while designing a healthy diet is vital since low GI foods assist maintain blood sugar levels by producing minimum blood glucose changes [4]. Choosing low GI foods is especially crucial for diabetic individuals because consuming high GI foods causes considerably more extreme glycemic responses, necessitating medication or insulin therapy [3,5]. It has been proven that exercise can help diabetes patients feel better. A forty-minute workout of swimming, weight lifting, jogging, or any combination of these, prior to a meal or 3 to 4 hours after a meal, can considerably lower the volunteer's post-prandial blood glucose levels, despite the fact that this is not the objective of this current study. It is, however, impracticable to replace hypoglycemic medicines with a daily workout routine [6-10].

To treat diabetes diseases without disrupting everyday activities, a wise lifestyle change is essential. The post-prandial blood glucose features of type 2 diabetes are captured using a biophysically-based model of an impulse-force-generated substantially damped oscillatory system. With a few adjustments, the model follows the general approach of the glucose-insulin interaction model (bolus injection of glucose), for which parameters may be easily evaluated, and a case study is presented to explore its possible uses. Instead of employing single food items with known GI values or a burdensome weighted mean of various ingredients in a meal, the test meal was made up of the subject's regularly consumed lunch. Based on the preliminary model 
results, a moderate lifestyle change was devised for the subject: swimming 20 laps for 40 minutes in a $25 \mathrm{~m}$ pool in the morning and dispensing $1 / 4$ of $5 \mathrm{mg}$ glyburide $1 / 2$ to 1 hour before lunch and dinner - allowing him to reduce $10 \%$ of his A1c level in six months and maintain the desired lower level for the following six months [11-15].

\section{Case Presentation}

$\mathrm{XYZ}$ is a 50 -year-old housewife who has had type 2 diabetes for two years. She had fasting blood glucose readings of 118$127 \mathrm{mg} / \mathrm{dl}$, which he defined as "borderline diabetes." She also linked blurred eyesight, excessive sweating, and increased thirst to the condition. She is not handicapped in any way.

\section{Physical Appearance}

Body mass index (BMI): $24.98 \mathrm{~kg} / \mathrm{m}^{2}$; weight: 66kg; height: $5^{\prime} 4^{\prime \prime}$. 150mg/dl fasting capillary glucose. Blood pressure: 130/90mmHg resting right arm; 130/80 mmHg sitting right arm. Pulse rate: 80 beats per minute; respirations rate: 18 per minute. Corrective lenses are worn in the eyes, and the pupils are equal and responsive to light and accommodation. No arteriolovenous nicking, fundi-clear. Thyroid gland is not palpable. Auscultation of the lungs reveals that they are clean. Heart: Regular rate and rhythm, no murmurs or gallops. There are no carotid bruits, and the femoral, popliteal, and dorsal is pedis pulses are all $2+$. Bilaterally. Neurological evaluation: forefoot vibratory sensibility decreased, ankle reflexes missing, monofilament.

\section{Medical History}

The Patient has also been suffering from hypertension for last three years. It was before three years of diagnosis of diabetes.

\section{Family Medical History}

Patient's mother was suffering from diabetes in past. Patient's elder sister and two younger brothers were also suffering from this disease. So it is found that it is inherited in their family.

\section{Medication and Diet}

Table 1: About years ago the doctor suggested her to take insulin as tablet. She is taking dose of mixture $30 \mathrm{HM}$ insulin twice a day.

\begin{tabular}{|c|c|}
\hline Medicine & Dosage \\
\hline Tab. Doanil & $5 \mathrm{mg}$ \\
\hline Tab. Biforge & $160 \mathrm{mg}$ \\
\hline Tab. Diajard & $500 \mathrm{mg}$ \\
\hline Insulin & $30 \mathrm{HM}$ \\
\hline
\end{tabular}

After diagnosis of diabetes, doctor advised following medicines and different times. Tab. Daonil $5 \mathrm{mg}$ before meal daily. After 2 years doctor suggested her to take Tab. Biforge 160mg for BP control and Tab. Diajard 500mg to increase blood glucose daily. About years ago the doctor suggested her to take insulin as tablet.
She is taking dose of mixture $30 \mathrm{HM}$ insulin twice a day. Please see Table 1.

She concerns with this following diet. Food groups are as follows: broccoli, carrots, greens, peppers, and tomatoes are examples of non-starchy vegetables. potatoes, maize, and green peas are examples of starchy foods. Oranges, melon, berries, apples, bananas, and grapes are examples of fruits. Grains-whole grains should account for at least half of your daily grains intake. Wheat, rice, oats, cornmeal, barley, and quinoa are all included. Bread, spaghetti, cereal, and tortillas are just a few examples. Protein like meat that is low in fat, without the skin, chicken or turkey, fish, eggs, peanuts and nuts. Chickpeas and split peas are examples of dried beans and peas. Tofu, for example, is a meat alternative. Nonfat or low-fat dairy. If you have lactose intolerance, drink milk or lactose-free milk, yoghurt, cheese.

\section{Discussion}

XYZ had type 2 diabetes and a slew of comorbidities, all of which necessitated therapy. The NP who provided his care's initial responsibility was to identify the most important healthcare issues and prioritize his medical treatment to solve them. Although XYZ claimed that his primary motivation for seeking diabetic specialty treatment was to lose weight, his abnormal glucose levels and hypertension required to be addressed on the initial visit. The patient and his wife agreed that seeing a dietician was the most important thing they could do. XYZ admitted that he didn't have any dietary expertise to assist him lose weight and that his present weight was unhealthy and "embarrassing." she recognized that excessive servings of bread and pasta were affecting his glucose control and agreed to begin improving his nutritional management by lowering his portion size by one-third during the week leading up to his dietary consultation. Losing weight would be a crucial first step in lowering his blood pressure.

The doctor prescribed biforage, 500mg twice a day, after assessing these choices and addressing the need for better glycemic management. XYZ was concerned about potential GI side effects and the need to avoid alcohol, but he felt that medication was important and that metformin was his best option. To lessen GI adverse effects, the doctor advised her to take the drug with food. The doctor also went over a titration strategy with the patient, which included increasing the dosage to $1,000 \mathrm{mg}$ twice a day over a 4 -week period. She offered the patient a written copy of the plan, which included a date and time for phone contact and medication review.

Women with type 2 diabetes will almost certainly need to adjust their treatment strategies and stick to carbohydratecontrolled diets. During pregnancy, many women will require insulin therapy and may need to stop taking other medications, such as blood pressure medications. During pregnancy, the risk of acquiring diabetic retinopathy or aggravating the condition increases. If you're pregnant or contemplating a pregnancy, see 
an ophthalmologist throughout each trimester, one year after delivery, or as recommended.

\section{Patients' Declaration of Interest}

The authors claim to have obtained all required parental consent forms. The patient(s) has/have given his/her/their consent for his/her/their photographs and other clinical details to be published in the journal by filling out the form. The parents are aware that their first and last names will not be published, and that every attempt will be made to keep their identities hidden, albeit complete anonymity cannot be guaranteed.

\section{References}

1. Ahern JA, Kruger DF, Gatcomb PM, Petit WA Jr, Tamborlane WV, et al. (1989) The Diabetes Control and Complications Trial (DCCT): the trial coordinator perspective. Diabetes Educ 15(3): 236-241.

2. Pearson L (2002) Fourteenth annual legislative update: how each state stands on legislative issues affecting advanced nursing practice. Nurse Practitioner 27: 10-22.

3. Mundinger MO, Kane RL, Lenz ER, Totten AM, Tsai WY, et al. (2000) Primary care outcomes in patients treated by nurse practitioners or physicians: a randomized trial. JAMA 283(1): 59-68.

4. Peters AL, Davidson MB, Ossorio RC (1995) Management of patients with diabetes by nurses with support of subspecialists. HMO Pract 9(1): 8-13.

5. Feldman CB (1998) Caring for feet: patients and nurse practitioners working together. Nurse Pract Forum 9(2): 87-93.
6. Nagusky D, Bell-Hart M (1991) Role of the nurse practitioner in diabetes and pregnancy management. Nurse Pract Forum 2(3): 196198.

7. Ahern JA, Ramchandani N, Cooper J, Himmel A, Silver D, et al. (2000) Using a primary nurse manager to implement DCCT recommendations in a large pediatric program. Diabetes Educ 26(6): 990-994.

8. Moyer A (1989) Caring for a child with diabetes: the effect of specialist nurse care on parents' needs and concerns. J Adv Nurs 14(7): 536-545.

9. Ziemer DC, Goldschmid MG, Mussey VC, Domin WS, Thule PM, et al. (1996) Diabetes in urban African Americans. III. Management of type II diabetes in a municipal hospital setting. Am J Med 101(1): 25-33.

10. American Diabetes Association (2003) Standards of medical care for patients with diabetes mellitus (Position Statement). Diabetes Care 25 (Suppl 1): S33-S49.

11. Inzucchi SE (2002) Oral antihyperglycemic therapy for type 2 diabetes. JAMA 287(3): 360-372.

12. Ahmann AJ, Riddle MC (2000) Oral hypoglycemic agents. In Medical Management of Diabetes Mellitus. In: Leahy JL, Clarck NG, Cefalu WT (Eds.), Marcel Dekker Inc, New York, USA, pp. 267-283.

13. Ahmann AJ, Riddle MC (2002) Current oral agents for type 2 diabetes. Post Grad Med 111: 32-46.

14. Conlon PC (2001) A practical approach to type 2 diabetes. Nurs Clin North Am 36: 193-202.

15. Clement S (1995) Diabetes self-management education. Diabetes Care 18: $1204-1214$

\section{Your next submission with Juniper Publishers} will reach you the below assets

- Quality Editorial service

- Swift Peer Review

- Reprints availability

- E-prints Service

- Manuscript Podcast for convenient understanding

- Global attainment for your research

- Manuscript accessibility in different formats

( Pdf, E-pub, Full Tsext, Audio)

- Unceasing customer service

Track the below URL for one-step submission

https://juniperpublishers.com/online-submission.php 